\title{
ESCALATION OF COMMITMENT IN NPD AND COST SAVING IT PROJECTS
}

\author{
Mark van der Pas and Niels van der Pas \\ European Center for Digital Transformation, Maastricht University \\ Tongersestraat 53, Maastricht, The Netherlands
}

\begin{abstract}
Stopping non promising projects as early as possible saves resources that can be allocated to more relevant investments or be saved to improve the bottom line of an organisation. Gated processes are in use in numerous organisations to decide on proceeding or cancelling a project. This study examines the consequences of the setup of the gatekeepers, the managers deciding on the gates, in these processes. Gatekeepers deciding on two consecutive gates are, according to the escalation of commitment theory, tended to confirm their initial decisions. They hold a higher approval rate for the consecutive decision as compared to a setup where the gates are approved by different gatekeepers. In this paper we present the results of, as far as we know, the first natural experiment on the escalation of commitment using 820 new product development and cost saving IT projects over a time span of 4.5 years. We found empirical evidence that escalation of commitment, as predicted in theory, leads to a higher approval rate of the consecutive gate. Organisations can mitigate this by changing the setup of the governance by avoiding the approval of two consecutive gates by the same gatekeeper. Furthermore, the data showed that large investment projects hold a significantly larger possibility to receive approvals (after an initial approval) than small investment projects. This indicates the importance of the initial gate approval. Finally, we studied the difference between cost saving and new product development projects and found no differences in their mortality rate nor in the approval rate of the consecutive gate.
\end{abstract}

\section{KEYWORDS}

Escalation of Commitment, IT Decision Making, Stage-Gate Process

\section{INTRODUCTION}

People are creative beings that come up with numerous ideas for new product development (NPD) or cost saving IT projects. Where some of these ideas are a straight success, a lot of them are (painful) failures. Failures because they never earned back their investment after they were launched or failures since they were aborted before launch. Whatever the type of failure, these projects have consumed resources that could have been reallocated towards successful new products, alternative improvements like process optimisation or bluntly be saved to improve the organisations' bottom-line.

In 2004 Cooper et al. claimed that products fail at an alarming rate; amongst others they found that only $21 \%$ of businesses' total NPD efforts meet their project objectives. In a more recent study Van der Pas and Furneaux (2015) found that $43 \%$ of new products deliver at least $80 \%$ of the expected revenue whereas $26 \%$ of new products never earned back more than the cost they occurred and thus delivered a negative bottom line value. On cost saving projects the results were better as $69 \%$ of the projects delivered at least $80 \%$ of the expected benefits and $7 \%$ of these projects generate a negative profit and loss effect.

The StageGate ${ }^{\circledR}$ process to manage ideas through key steps into launched products is an instrument to organise decision making and is used to evaluate, select or cancel projects (Cooper 2008). The StageGate ${ }^{\circledR}$ process is focused on the development of new products, this kind of processes are also used for other project types like cost saving or security improvements (see for an overview Van der Pas 2017). Decision points separating the phases are known as 'gates', 'milestones' and 'tollgates' (Cooper 2001, Chao and Ishii 2005) and determine whether a project migrates into the next stage or is terminated. These processes are described as Stage-Gated Processes in this paper.

Optimising decision making within the Stage-Gated process could significantly improve the impact of cost saving and NPD projects. If we focus on project cost avoidance then the cost of each failed new product 
or IT project is not the same, nevertheless it is generally accepted that projects that need to be stopped are to be cancelled as early as possible (Unger et al., 2012). The Stage-Gated process can be used for this purpose and in this paper we focus on one specific aspect of decision making: escalation of commitment. Eliens et al. (2018) described escalation of commitment as the unwillingness of a gatekeeper to let go of a fruitless new product development project. Escalation of commitment occurs when two consecutive gates are approved by the same gatekeeper and postpones the cancellation of failing projects. Although defined as an issue within NPD we study this for both NPD as well as cost saving IT projects. Several cancellation rates are published (Barczak et al., 2009; Hossain \& Islam 2015). Unlike this paper they did not study escalation of commitment.

This paper describes a natural experiment within an organisation that switched their gatekeeper structure. In one period the organisation used a structure that avoided escalation of commitment by assigning different gatekeepers to the first gates. In the other period the gates were approved by the same gatekeeper which could lead to escalation of commitment. We found clear evidence of escalation of commitment in organisation and provided suggestions to improve the performance of NPD and cost saving IT projects.

\section{THEORY AND HYPOTHESES}

Cancelling unpromising projects as early as possible turned out to be challenging in daily practice (Sarangee et al. 2014; Schmidt and Calantone, 2002). The gates of the Stage-Gated process could be used to stop or cancel projects. The managers deciding on the gates are called the gatekeepers (Cooper et al. 1994). As claimed by Staw and Ross (1987) 'individuals may have the tendency to become locked into a course of action, throwing good money after bad money'. For that, escalation of commitment could occur when two consecutive gates are approved by the same gatekeeper. In taking the second decision the gatekeeper should ignore sunk cost as they are irrecoverable, nevertheless the gatekeeper is, whilst deciding on the second decision, biased by his first decision. By confirming his earlier approval on the previous gate he would consciously or unconsciously confirm the correctness of his initial decision. The effect would be a delay of the cancellation of an unpromising project. Based on this we expect a higher approval rate of the consecutive gate in case both gates are approved by the same gatekeeper. This is tested in the first hypothesis.

H1. The approval likelihood of a gate is higher when the preceding gate was approved by the same gatekeeper

Not all projects hold the same investment volume. The larger the project size the higher the sunk costs for stopping a project. Based on this it can be expected that the reconfirmation of the second gate is higher for large investments than for smaller. On the other hand, the larger the investment size, the better a gatekeeper is expected to consider the approval of the second gate and for that to overcome the escalation of commitment. We expect the forces to balance and to find no difference for the approval of a preceding gate for large as compared to smaller investments.

H2. Investment size holds no influence on the approval likelihood of the second gate by the same gatekeeper

IT projects related to new product development hold higher risks than cost saving projects. E.g. Bower (1986) found that cost saving projects deliver on average $110 \%$ of the expected value whereas NPD projects deliver $10 \%$ of that value. The time during the Stage-Gated process enables an organisation to gain additional information that can be used to reevaluate the risk. Knowing that NPD investments hold a higher risk and that additional information on risks is found during the Stage-Gated process, we expect a higher mortality rate for NPD than for cost saving projects.

\section{H3. New product development IT projects hold a higher mortality rate than cost saving IT projects}

In case two consecutive gates are to be approved by the same gatekeeper and this leads to a higher approver rate of the second gate, then this could reduce the mortality rate over those gates. A lower mortality rate indicates that the disadvantage of escalation of commitment could be higher for NPD than for cost saving IT projects. Knowing this difference could trigger gatekeepers of NPD projects to be more conscious 
about escalation of commitment and for that mitigate it. Based on interviews with practitioners and the modest knowledge in organisations on escalation of commitment we expect organisations not to leverage this knowledge and for that we expect no difference between the two project categories. This leads to $\mathrm{H} 4$ :

H4. Escalation commitment does not differ between NPD and cost optimizing IT projects

In the next section we describe the methodology to test these hypotheses; then the results are described.

\section{METHODOLOGY}

The data used for this study comes from a European telecommunication organisation with an annual revenue of more than 2 billion Euros and capital investments exceeding 100 million Euro per anno. The organization offered data for all projects that were managed over the process from November 18th 2014, as it implemented the current gated structure upto March 1st 2019. The gates and stages of the process did not change during that timeframe and the process was used for IT projects. The process holds in total 6 gates; the third gate is the go on implementation and on average $79.8 \%$ of the project resources are spend after that gate. The last three gates are technical readiness, commercial launch and project closure.

As from October 2016 the first two gates are approved by one gatekeeper. From November 2014 up to October 2016 the first gate was approved by a different gatekeeper than the second gate. Based on this set up a lower escalation of commitment is expected on the first period (up to October 2016) than in the second period.

For H1 we used 820 projects with an approval for the first gate; 633 of these projects were implemented and 187 were cancelled. 712 of the 812 projects also received an approval for the second gate $(86.7 \%)$. In case a gate was initially rejected but in a later request approved then the rejection was excluded from our analysis and the gate counted as an approved gate. We compared the percentage of these projects that got an approval for the second gate in the first period with the same percentage for the second period. We tested H1 and all hypotheses by comparing datasets with each other. The comparison is made using a t-test.

The size of the project for $\mathrm{H} 2$ was determined based on the budget. We allocated the 320 projects in the period with expected escalation of commitment into three classes. E.g. 192 projects held an investment volume of less than or equal to 25,000 Euro and 128 held a higher investment volume (see table 1).

Table 1. Allocation of the Projects into Investment Categories

\begin{tabular}{lll}
\hline Definition of 'large project & Amount of small projects & Amount of large projects \\
\hline$>25,000$ Euro & 192 & 128 \\
$>$ 50,000 Euro & 215 & 105 \\
$>100,000$ Euro & 240 & 80 \\
\hline
\end{tabular}

In $\mathrm{H} 2$ we tested for each of the three categories the difference of the approval rate of the second gate.

For H3 we split the dataset of 820 projects into two project categories by using the project initiator. The marketing and sales-initiated (and financed) projects are allocated to the NPD category whereas all other projects initiated by e.g. operations, HR, finance and technology are allocated to the cost saving category. This is a very broad clustering where e.g. sales enhancements and sales channel investments such as e- or $\mathrm{m}$-commerce are allocated to the new product development category. Investments in technology, scalability, architecture, security etc. are all allocated to the brought cost saving category. The mortality rate was calculated based on all projects that received an approval for the first gate. It was defined as the ratio of cancelled projects as compared to all projects.

The dataset from the period with possible escalation of commitment was also used for $\mathrm{H} 4$ and we studied the difference between the approval rate of the consecutive gate for NPD projects and compared that to the same approval rate for cost saving projects. 


\section{RESULTS}

In the first period 320 projects received an approval for the first gate $72.8 \%$ of these also received an approval of the second gate. $95.6 \%$ of the 501 projects in period two received an approval for the first two gates. Due to the large difference in variance $(0.20$ and 0.04$)$ we used a two-sample t-test assuming different variances and tested whether the difference of means of these two datasets is 0 . This was rejected with an extremely low p-value (9.55 E-17). Based on this we accept H1.

Large projects hold a stronger likelihood of approval of the consecutive gate than smaller projects. $96.1 \%$ of projects over 25,000 Euro received an approval for the second gate whereas $57.6 \%$ of the projects with an investment volume below 25.000 Euro received an approval for that gate. Also, the variance differs strongly $(0.25$ and 0.04$)$. The $p$-value of the t-test for equal means assuming inequal variances generated a low $p$-value (1.72 E-19). Also, the other investment size categories held a low p-value (6.32 E-16 for 50,000 Euro and 5.55 E-13 for 100,000 Euro). Based on this $\mathrm{H} 2$ was rejected.

The mortality rate of both NPD and cost saving IT projects in the studied data was 0.23 meaning that on average 77 of the 100 projects with a first gate approval are finished. Not only the means, but also the variances are identical (0.18), this leads to a high p-value of 0.42 indicating no differences to the mortality rate of NPD and cost saving IT projects. We reject $\mathrm{H} 3$.

$95.5 \%$ of cost saving IT projects received an approval of the consecutive gate (variance 0.04); whereas $95.7 \%$ of the NPD IT projects received such an approval (variance 0.04). The two-sample t-test assuming equal variance for a mean difference of 0 returned a one-tail p-value of 0.45 . The lack of difference between both data sets allowed us to accept $\mathrm{H} 4$.

\section{CONCLUSION}

In this study we found a clear correlation between the likelihood of approval of a consecutive gate and governance of the Stage-Gated process. In a set up where one gatekeeper is empowered to approve two consecutive gates for a project the likelihood of approving the second gate is significantly higher than in case the setup uses two different gatekeepers. This indicates that a sharp mortality rate can be created by using a governance where consecutive gates are not approved by the same gatekeeper.

A strong confirmation rate of initial decisions as found in the set up where a gatekeeper is empowered to approve multiple gates, strengthens the importance of the initial gate approval. In case the setup cannot be changed, performance improvements of the process should be focused on that first gate.

Furthermore, we found that large investment projects hold a higher possibility to receive an approval for the second gate in case the gatekeeper approved the first gate too. This supports the idea that an increase in the sunk cost reduces the likelihood to cancel a project.

Finally, we found no difference between cost saving and NPD IT projects. Escalation of commitment seems independent from the project category despite their completely different risk structure.

\section{LIMITATIONS AND SUGGESTIONS FOR FUTURE RESEARCH}

This study is based on data of one organisation, other organisations or even other agents within the same organisation could show different results. Generalising the conclusions for other organisations, especially organisations in different branches, different continents and different sizes should be done with utmost care. Since the setup of this study is now known it can be easily repeated by organisations knowing the required input data. Replicating this study and performing a meta-analysis on those studies would increase the robustness of the findings as well as the level at which they can be generalised.

The differences found could also be explained by intermediate variables. These variables are not known to the authors but could be studied in future research. Furthermore, we illustrated correlations, the statistical methods used did not study the causality of these relations. 
This study focused on the approval of two consecutive gates in the Stage-Gated process and used for H3 the information whether a project was cancelled or finished. Future research should enhance this by including the expected profitability as well as the realised profitability of the IT project. Using more than the two investment categories from this study, NPD and cost saving IT projects, such as strategic, sales expansion or legally obliged investments could also be studied in future research.

We furthermore suggest a study to the awareness of escalation of commitment in Stage-Gated processes. Perhaps the Theory of Planned Behavior (Ajzen 1991) can be used to study behavior, intention as well as attitude, subjective norm and perceived behavioral control on neglecting sunk costs in future Stage-Gated Process decisions.

Finally, we suggest studying the usage of machine learning to support gatekeepers in deciding on the gates. Machine learning could be used to increase the 'objectiveness' of decision making and by doing so be a counter action against escalation of commitment.

\section{ACKNOWLEDGEMENT}

The authors wish to thank the participating organisation for allowing us to study their data. Furthermore, they wish to thank the team developing the portfolio management tooling which delivered the data for this study 'at the push of a button'.

\section{REFERENCES}

Ajzen, I., 1991. The theory of planned behavior. Organizational behavior and human decision processes: a journal of fundamental research and theory in applied psychology, 50: 179-211.

Barczak, G., A. Griffin, and K.B. Kahn, 2009. Perspective: Trends and Drivers of Success in NPD Practices: Results of the 2003 PDMA Best Practices Study. Journal of Product Innovation Management 26(1): 3-23.

Bower, J. L., 1986. Managing the Resource Allocation Process. Boston: Harvard Business School.

Chao, L.P. and K. Ishii, 2005. Design process error proofing, benchmarking gate and phased review life-cycle models. IDETC/CIE 2005, Long Beach, CA, USA, September 24-28.

Cooper, R. G., 1994. Third-generation new product processes. Journal of Product Innovation Management 11 (1): 3-14.

Cooper, R. G., 2008. Perspective: The stage-gateVR idea-to-launch process-update, what's new, and Nextgen systems. Journal of Product Innovation Management 25(3): 213-232.

Cooper, R. G., S. J. Edgett, and E. J. Kleinschmidt, 2004. Benchmarking best NPD practices I. Research-Technology Management 47: 31-43.

Cooper, R.G., 2001. Winning at new products: accelerating the process from idea to launch. Cambridge Massachusetts: Perseus publishing.

Eliens, R., K. Eling, S. Gelper and F. Langerak, 2018. Rational versus intuitive gatekeeping: escalation of commitment in the front end of NPD. Journal of Product Innovation Management 35(6): 890-907.

Hossain, M., and K. M. Z. Islam. 2015. Generating ideas on online platforms: A case study of "My Starbucks Idea." Arab Economic and Business Journal 10(2): 102-11.

Pas, van der M. and B. Furneaux, 2015. Improving the Predictability of IT investment Business Value. European Conference on Information Systems 2015, paper 190, http://aisel.aisnet.org/ecis2015_cr/190/

Pas, van der M., 2017. Speeding up time-to-market of it investments. 10th IADIS International Conference on Information Systems 2017, full paper: 155-162.

Sarangee, K. R., J. L. Woolley, J. B. Schmidt, and E. Long, 2014. De-escalation mechanisms in high-technology product innovation. Journal of Product Innovation Management 31(5): 1023-1038.

Schmidt, J. B., and R. J. Calantone, 2002. Escalation of commitment during new product development. Journal of the Academy of Marketing Science 30(2): 103-118.

Staw, B.M., and J. Ross,1987. Behavior in Escalation Situations: Antecedents, Prototypes and Solutions, in Research in Organizational Behavior, Eds. L.L. Cummuings and Barry M.Staw Greenwich, CT: JAI: 39-38.

Unger, B.N., A. Kock, H.G. Gemünden, and D. Jonas, 2012. Enforcing strategic fit of project portfolios by project termination: An empirical study on senior management involvement. International Journal of Project Management 30(6): 675-85. 